A. R. WONG, N. J. FASTUCA, V. W. MAK, J. K. KERKOVIUS, S. M. STEVENSON,

S. E. REISMAN* (CALIFORNIA INSTITUTE OF TECHNOLOGY, PASADENA, USA)

Total Syntheses of the $\mathrm{C}_{19}$ Diterpenoid Alkaloids (-)-Talatisamine, (-)-Liljestrandisine, and (-)-Liljestrandinine by a Fragment Coupling Approach

ACS Cent. Sci. 2021, 7, 1311-1316, DOI: 10.1021/acscentsci.1c00540.

\title{
Synthesis of (-)-Talatisamine and (-)-Liljestrandisine
}
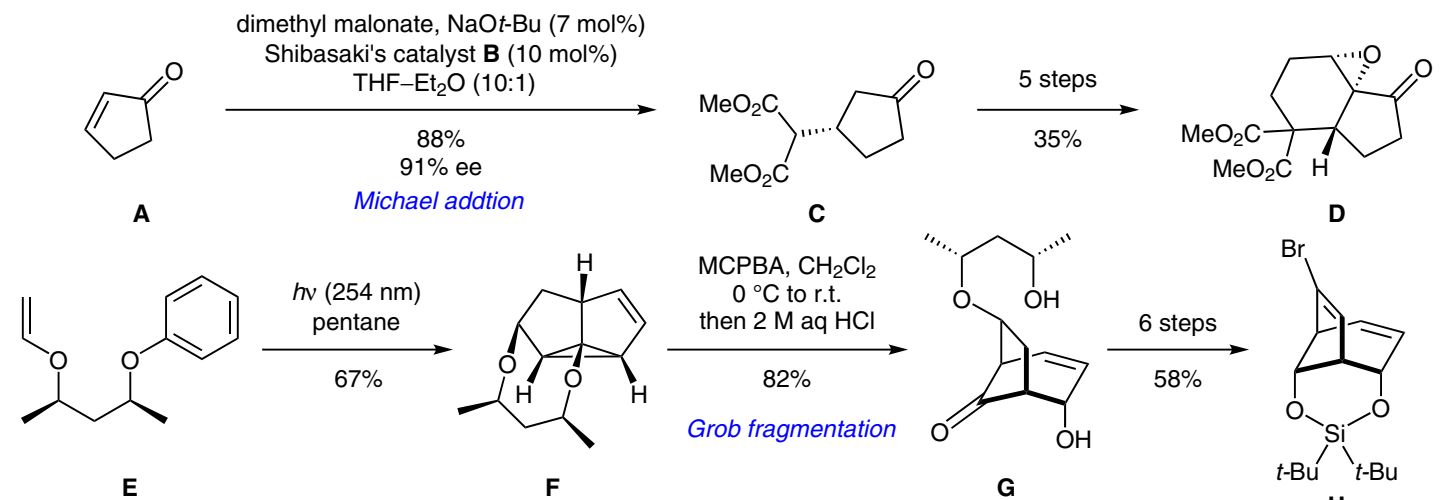

$\mathbf{E}$

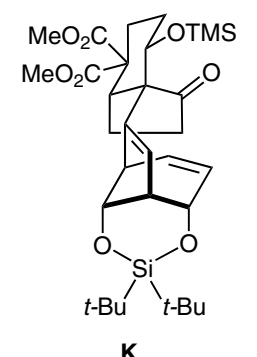

\begin{tabular}{l|l}
\multicolumn{2}{c}{$\mathbf{K}$} \\
13 steps & $11 \%$
\end{tabular}

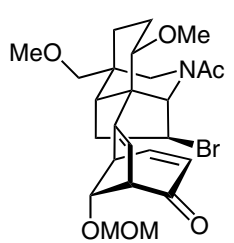

L
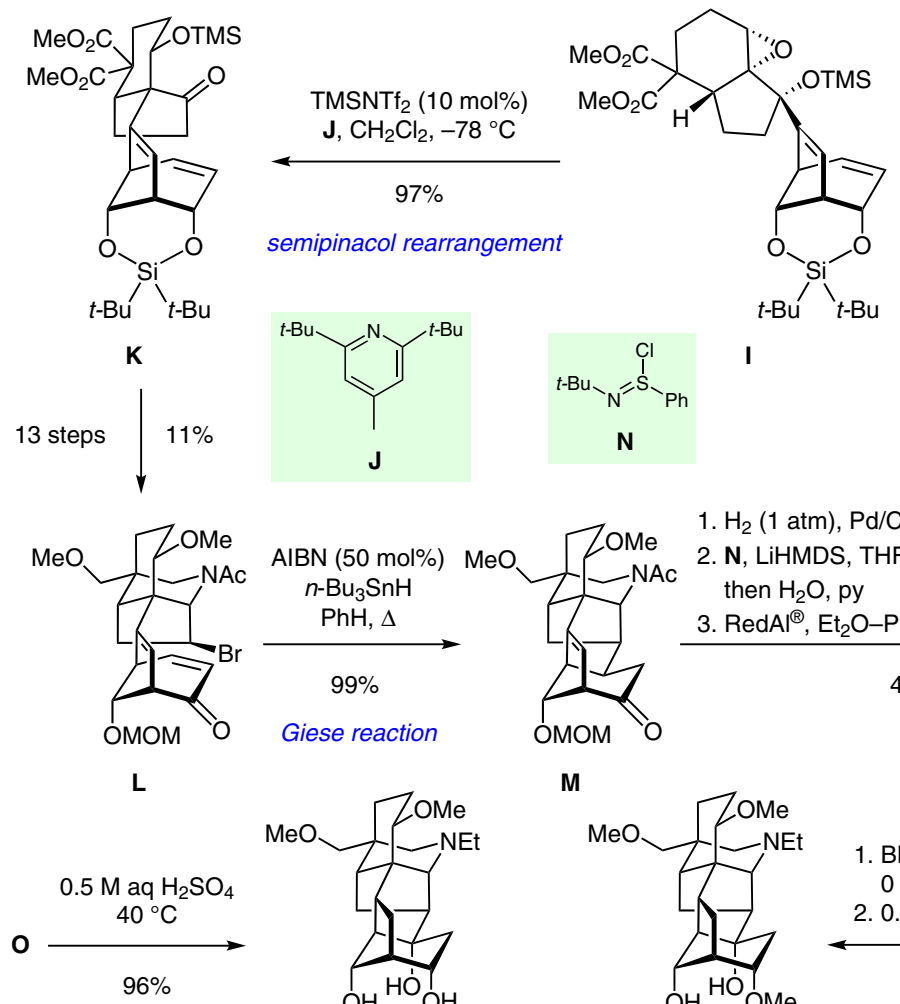

$$
t-\mathrm{Bu}_{-\mathrm{N}} \stackrel{\mathrm{Cl}}{\mathrm{Cl}} \mathrm{S}^{\mathrm{C}} \mathrm{Ph}
$$<smiles>C[C@H](O)C[C@H](C)OC1C(=O)C2C=CC1C2O</smiles>

G

\section{Category}

Synthesis of Natural

Products and

Potential Drugs

\section{Key words}

aconitine-type alkaloids

Giese reaction

semipinacol

rearrangement

(-)-talatisamine

(-)-liljestrandisine

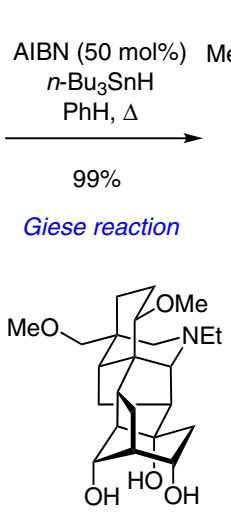

$(-)$-Liljestrandisine

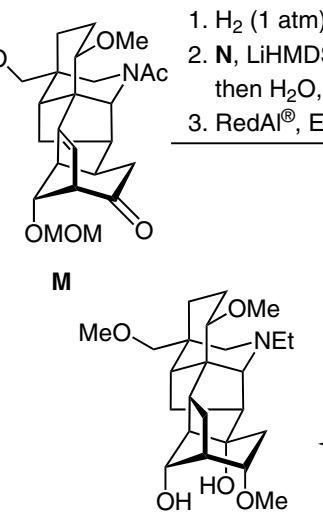

$(-)$-Talatisamine

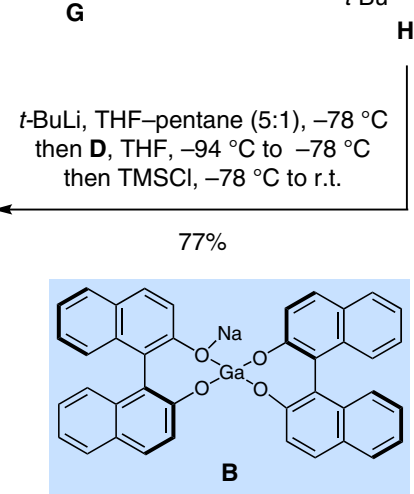

D
Significance: Reisman and co-workers report a convergent fragment coupling approach to the aconitine-type alkaloids (-)-talatisamine, (-)-liljestrandisine, and (-)-liljestrandinine. The structure of (-)-liljestrandisine was revised.
Comment: 1,2-Addition of lithiated bromide $\mathbf{H}$ to ketone $\mathbf{D}$ gave $\mathbf{I}$ after in situ TMS protection.

$\mathrm{TMSNTf}_{2}$ mediated the key semipinacol rearrangement that led to ketone $\mathbf{K}$. This was elaborated to the full carbon skeleton of the natural product in 14 steps. 